Acta Univ. Sapientiae, Film and Media Studies, 17 (2019) 131-142

DOI: $10.2478 /$ ausfm-2019-0019

\title{
In-Betweenness and Interactional Presence in Adrian Sitaru's VR Play, Illegitimate
}

\author{
Otília Ármeán \\ Sapientia Hungarian University of Transylvania (Târgu Mureş, Romania) \\ E-mail: armeano@ms.sapientia.ro
}

\begin{abstract}
This paper will present the role of the loops and the peculiarities of the mixed reality experience in the case of the performance of Illegitimate (stage adaptation by Adrian Sitaru, based on an original text by Adrian Sitaru and Alina Grigore). The author argues that the loops, defined by Manovich as "a new narrative form appropriate for the computer age" are also the key for the possible reality switches and joinings.
\end{abstract}

Keywords: VR technology in theatre, presence, immersion, in-betweenness.

Virtual Reality enables us to be present in a physically absent world. In the VR-play Illegitimate (Adrian Sitaru, 2018, Hungarian Theatre of Cluj), a theatre performance that combines live action on stage with VR technology, viewers can simultaneously be present in two realities and decide which is more convincing or more stimulating for them. This awareness works against the immersion, but at the same time gives the viewer a feeling of in-betweenness. According to the director, the performance is about "a disintegrated, confused family, lacking the presence of a mother, where each person struggles with their own prejudices and is right in their own way" (Sitaru 2018). The father, Victor, is a strong, authoritarian figure, who wants to hold control over the lives of others - a position that used to be proper when his children were young, but is not suitable any more for his adult children. Dávid, Szása, Rómeó and Hilda are all grown-ups now, having their own problems and difficult decisions to make. The very different points of view are presented sensitively through the conversations the family is having during a family lunch. All conflicts emerge when it comes to the topic of abortion, and the role played by the father as a medic in the tragedy of women who wanted to have abortions in the communist era by reporting on them. It turns out that the family's house, their home, can be considered a reward for the father's cooperation with the former communist regime, obtained therefore in an illegitimate way. 
What is dazzling for the spectator is that we peep in the world of this family, we see how the different characters act and protect their standpoints, how they fight their corner. And everyone is right within the confines of his/her own world. Only the spectator is able to see how these separate worlds intersect and how the intersections and overlaps create a special space of in-betweenness. Sitaru accentuates the parallel structure of the different realities: "it is a miniature image of the world we live in, of our blindness, and inevitable ignorance, due to the way we perceive things differently and in a deformed way, may we be ordinary people, or philosophers. We go through life wearing invisible goggles, blinkers or coloured glasses, we only see what we want and it becomes convenient for us to only notice what we have learnt to see" (Sitaru 2018).

The technical parameters of this theatre performance, the characteristics of the stage and the VR-headsets that are used to enable the audience to assist simultaneously to the two performances of the same play are all helpful tools to make the parallelisms and the in-betweenness happen. The audience will not only conclude on these terms as practical tools for understanding the performance but will also experience these types of connections through the decisions taken as a participant at the performance.

The VR-glasses in this presentation make it possible for the audience to be present in a reality that already happened and is not present any more. It was a "here and now" when they captured it; it was processed afterwards so that we can perceive it as a virtual reality trough the glasses: what we see is realistic, it has all the elaborate details. Our position as viewers enables us to take on the roles of insider participants. We are on the stage, close to the presented situation. We can even see the landscape outside the stage through a rear window. At a certain point, it starts to snow.

If we take off the glasses and look at the show proceeding in front of our eyes, we can observe that the set is unfinished. As if two pictures have not been assembled yet, and the green background indicates that there will be another layer that will include all the details, space and time stamps. There is even a curtain that has not yet been pulled up. [Fig. 1.] The presence of the actors and the live action on stage makes us forget about the disturbing deficiencies of the setting, while our presence in the VR and the closeness to the actors makes us forget about the headsets and technology. 


\section{Presence}

Why is one specific Virtual Reality more immersive than another? That is a question of the VR-studies which implies the notions of presence, uninterruptedness, absorption, total concentration. Regarding the impression of reality of virtual spaces, the frame of reference is always our actual reality: it needs to have realistic details, to appeal to all the senses so one could not tell the difference between the virtual and the physical, to grant an interruption-free access, to be able to forget the technological support.

Immersion calls for undivided attention and presence, but presence is sometimes necessarily divided: between physical and virtual, between actual and virtual. Virtual reality in this sense is not something new either: mixed realities and multiple presences were experienced in the Victorian time of peep eggs, too. Or we can specify with Oliver Grau: "virtual reality forms part of the core of the relationship of humans to images. The idea goes back at least as far as the classical world, and it now reappears in the immersion strategies of present-day virtual art" (quoted by Dixon 2007, 364).

Hans Ulrich Gumbrecht defines presence as "a spatial relationship to the world and its objects. [...] Something that is 'present' is supposed to be tangible for human hands, which implies that, conversely, it can have an immediate impact on human bodies" (2004, xiii). Gumbrecht starts from the certitude that presence emerges from the materiality, from the characteristics of the medium. Absent presence occurs, according to Gergen, when "one is physically present but is absorbed by a technically mediated world of elsewhere. Typically it is a world of relationships, both active and vicarious, within which domains of meaning are being created and sustained" (2009, 227). Meanings and use of technology typically work against presence, but Gergen admits there is technology that can be used in "extending the power of endogenous realities," but also to interweave different worlds and realities $(2009,238)$. Carlson et al. suggest that "technology does not need to be transparent for an audience or performer in order to experience and can in fact aid in creating, blending, and restricting containers of presence" $(2018,108)$.

Hybrid and distributed performance stages combine and overlay real, virtual and augmented environments in what is considered mixed reality. Unlike virtual reality, this "offers the possibility of creating such hybrid performative and participatory environments in which real and physical data appear, but not so much as integrated into one another but rather juxtaposed on top of or next to each other" (Benford and Giannachi 2011, 5). In my interpretation of Illegitimate, 
the audience is encouraged to gain this multiple presence through the hidden commands of the loops used in the performance. From the perspective of the theatre, loops can be the tools that achieve ruptures in the presented dramatic world, insofar as they grant an uncertain, fragmented point of view.

\section{A Possible Path through the Mixed Reality Performance}

We are instructed before the beginning of the show that we can decide for ourselves if we use the headsets or we follow the show on the stage. In the here and now of the actual presentation, the two versions of the performance can be perceived simultaneously if one does not wish to make an exclusive choice between the stage reality and the virtual reality.

In the case of Illegitimate, we are definitely encountering a mixed reality, where the two realities, the theatrical and the virtual are put in a parallel position without an exclusive relation. VR-play means here a theatre performance that combines live action on stage with VR technology. The audience experiences different levels of overlaying, of traversing signals. Benford and Giannachi also mention that "in mixed reality performances audiences are often encouraged to move from one role to another within the same work, thus gaining multiple perspectives over a given experience" $(2011,7)$.

Originally, I wanted to follow only the VR performance, then I was worried about missing out on something important if I just follow the show with the glasses on. I definitely wanted the whole experience, and prepared myself to be aware of possible instructions to watch the show with glasses or rather without them.

We can follow the same story line through the glasses and on the stage. In the story we are in the midst of a family debate first about things that need to be done around the house, second about the possible origins of Christian rituals, third about quantum mechanics, Eckhart Tolle and Buddhism and finally about abortion. The father figure is always convinced of his own truth, whether it is about mythology or about how his kids should live their lives. The young adults have different opinions, different viewpoints and feelings. The father says that his action to prevent abortion was appropriate. The others say that he was right in saying no to abortion, but incorrect in the other preventive action, in the denunciation. And that the father was definitely wrong in taking advantage of this situation, namely accepting the house as a reward for the denunciations. Through this debate we get an insight into the life of this family; a variety of realities 
appear in front of us, a system of relations that would roughly be destroyed by deciding who is right. But everyone is working on enforcing their own truth. Only Hilda appears as the one who sees all realities and viewpoints, she agrees partly with Szása, partly with Dávid, but in some regards with Viktor too.

As Andrea Tompa writes: "the VR glasses bring this world very close to the audience, without changing the fixed theatrical focus (that is, there are no closeups, no cuts, only long shots), yet it is as if we were looking through a microscope and closely studying a fantastically alive, active anthill living an intense life. Because that was what was literally happening before our very own eyes” (2018). We are immersed in the presented possible reality, and the experience allows us to remain in an observer-position without the pressure of judging the ideas. We don't have to take sides or to decide what we think about our own prejudices.

But, at a certain point, the narrative begins to repeat itself. [Fig. 2.] The loop can have an estranging effect in a theatrical performance, so our perception is distorted into seeing the play as something not finished yet, like an experiment or exercise. Manovich defines loops as "a new narrative form appropriate for the computer age" $(2001,317)$, as "sequences of images featuring complete actions that can be played repeatedly" $(2001,297)$. The repetition in the narrative makes it clear that we are participants in a performance, it brings the medium in focus. The loop in this case suggests the extent to which the characters get stuck in situations and they cannot resolve their problems. With the words of the director: "we are turning around and around, in a circle, repetitively, and live parallel realities in our minds" (Sitaru 2018).

Therefore, a new sequence repetition in the VR can cause us to switch to the stage. (See Fig. 3 for the participant trajectory diagram.) On the stage, an alternative end of the story is just about to happen, which is not legitimate in the light of the foregoing. The father's changed attitudes, the recognition of the opinions of the others, and the embedding of his own into a personal story, telling the story of what happened to him and his partner when they had chosen an abortion, and that particular moment of their lives changes the outcome of the debate. The emotions are settling, the stage is turning silent, music plays quietly. [Fig. 2.]

This silence will be the new switch, a signal to put on the glasses and find out what is going on in the VR world of the play. The loop has expired, long ago or just now, I don't know, but what is happening just now is incredibly exciting. Dávid, the oldest son, is acting as if he were insane. Paradoxically, this means that he starts to see himself precisely as an actor, claiming that there are viewers staring at him. He acquires some (illegitimate) form of superpower, turns VR walls into a 
plain green-box background, senses the virtual fourth wall separating the actors from viewers as existent, real. He faces the viewer and sees the audience. He is mad, he comes very close to the VR-viewer, I feel that I have no personal space any more. Someone from behind tries to calm Dávid, to distract him with food, asking him, "Do you want more?" That is the point when VR and theatre merge again, for the last time. Because this is the last sentence of the performance, and actually it applies to the whole presentation.

It sounds like an instruction, even a warning. If I want to understand the parallelism, the slips and the switches between the two realities, I should then probably go through the whole VR-experience again (although I felt so threatened by Dávid's failure that I almost removed my glasses). "Do you want more?” - echoes in my ears. But if I take part in this performance again, I myself will enter in a loop.

The performance, however, presents this loop, this repetition, this being stuck in a loop as a possibility, and probably the only possibility to recognize our presuppositions, the limiting glasses of our truths. In the mixed reality of this performance we are not simply immersed in an alternate reality, but initiated in the parallelism of different realities and normalities that compete for our attention.

\section{Hodological Space and the Role of Different Trajectories}

Kurt Lewin proposed the term of hodological space for defining the psychological dynamic field unfolding around the acting individuals, "a kind of space which is defined through the possible paths between points" $(1933,339)$. A person gains presence through their interactions with the environment, obstacles or barriers, following different pathways and constructing the space via movements along different paths. Steve Benford and Gabriella Giannachi (2008, 76-78) argue that user experience journeys can be described with three main trajectory types: canonical trajectories (i.e., proposed by the designers of that mixed reality experience), participant trajectories (i.e., pathways actualized in a concrete experience) and historic trajectories (i.e., remembered, exposed, remediated trajectories). While the originators proposed this theory as a sensitizing concept, and a tool enabling and supporting the design of such interactive humancomputer interfaces (for example as a vehicle for compiling craft knowledge or as a tool for new dramaturgies), it can be used also as a theoretical framework (see Velt, Benford and Reeves 2017, 1098), which helps students, technologists, performers or users to understand the nature of mixed reality environments, and the "transformation of theatrical space" (Dixon 2007, 361). 
The trajectories conceptual framework will serve here as a tool for emphasizing the viewer's movements between the two strata of the performance. In the case of this performance the visitor remains physically in the static position of a viewer, but virtually there is a possibility to become a "walker," a participant, who acquires interactional presence and is capable to move between the two realities presented in the performance, namely to choose between the stage-view or the VR-glass-view. These are two perspectives on the same story, happening in the more or less same space, showing the same characters (but it is worth mentioning that two roles are played in different performances by two different actresses, so it can happen that somebody sees the performance with two or even four different persons in the stage- and in the VR-performance acting the same two roles).

The space on the stage is defined by a great table in the living room, where the family gathers. A part of the setting is removed, functioning only as a sign of how the interior of the house could be imagined. Mobile phones and tablets play an important role in the everyday interactions between the characters. They also point to a multiplicity of realities and virtual spaces, hybridizing the here and now coordinates of the time and space universe. What we see and hear is already a multiverse. The space of the VR has a more elaborated stage, but the picture remains unfocused compared to the experience offered by a movie screening due to the technological characteristics. The distance between spectator and VR universe diminishes, the spectator is forced to participate in creating the space, for example finding familiar objects, but he is also allowed to be a simple observer without the possibility to interact, to intervene. However, the consequences of the spectators' decisions, taken only in their minds, influence the nature of the trajectories they choose to navigate through the performance, and this is exactly what hodological space is about. "Above all, one has to determine the directions and paths not physically but psychobiologically in the meaning of hodological space." (Lewin 1933, 335.) In that hodological space, the spectator becomes a participant, and influences the others who are also actively present in that space (for example, by frequently taking off and putting on the VR-headsets).

The first canonical trajectory is to participate in the performance without the glasses [Fig. 2, Theatre], the second one is to participate with the glasses on [Fig. 2, VR]. These are two different trajectories, but the outcomes are not so different. On the theatrical stage, after the conflict, the father walks out the door, but then he comes back into the living room and sits down at the table as if nothing happened. He tells a very personal story, so all participants reach a 
state of mutual understanding and closeness. On the VR-stage the plot shows a second loop, but the father manages to avoid conflict this time. We are witnessing after this the out-of-reality experience of the eldest son, Dávid, which makes us understand a little more about the nature of this performance.

Beside these two canonical trajectories there is probably a third one as well, a mixed type, where the participant tries to switch between the first two trajectories. The loops or the silence can then be considered signals for changing from the theatrical performance to the VR-performance.

Participant trajectories are concrete, happening during the actual performance, but they can be very digressive, disorderly and even rebellious. Above, I tried to reproduce my first experience with this performance, when I was not even sure for how long the second loop was extending, or if it was accurate or altered in relation to the repeated story part. (See this path in [Fig. 3].) Moreover, the activity of changing the perspective (putting VR-glasses on and taking them off) enables the participant to check the other participants and their activities (somebody sitting next to me was even able to scroll through her photo-feed on her phone).

Historic trajectories are in some extent exemplary, specific, made available for ulterior discussions. "The historic trajectory describes how an experience is captured and recounted afterwards. Historic trajectories enable us to reflect on our experience and recount them to others at a later time." (Benford 2013.) It develops when an experience is documented with personal stories told after the performance, with photos made during the experience, with posts on official or personal media platforms. In the conversion of participant trajectories to historic ones, they can overlap with temporal distinctions or other aspects that result in other types of trajectories (i.e., temporal, interleaved, local, dropout trajectories) (Velt, Benford and Reeves 2017, 1093, 1096).

In the attempt to convert my accidental participant trajectory to a conscious historic one I found that the concept of hodological space is a fitting descriptor of the immersion and presence characterizing the specific activity of the participants when attending the performance of Illegitimate.

What we see and experience here is a specific space-construction, where the spectator is placed outside the theatrical stage, but also inside the VR-stage. The activity of the participant requires decisions to construct personal participant trajectories, and with the trajectory a unique and perhaps unrepeatable variation of the performance will be perceived. This participant-made version is based on the detection of the signals for switching (for example, the loops or the nonactivity, silence on stage), on the influence of other participants' activities (do 
they switch from theatre to VR or not), on the social sensitivity of the participant towards the story (physical and verbal aggression will probably compel the participant to make a decision about the trajectory, too). Kurt Lewin's notion of hodological space is appropriate when understanding the way a new kind of "contact space" arises that implies "a matter of senses that emerges from between the inside of the self and the outside of the world, and also from between different temporalities and spatialities" (Laine 2006, 130).

The in-betweenness experienced during the performance of Illegitimate is more accurately described in hodological terms. In the participant trajectories spectators are constantly between the two stages, the two different spaces, between the temporality of the story, the time of the plot, the time evoked by the stories told in the plot, between different attitudes, preferences, perspectives, moving towards understanding, acceptance, but also willing to define what their personal viewpoint is. Multiplicity and fluidity are not just metaphors for the experience, they are also concrete qualities of this performance. A hodological space creates the possibility to move, to act, to be in-between. It is a space that opens between the lines, offering more and more legitimate versions of the truth that enable acceptance, closeness and cease the compelling force of the loops or other dependences. How we deal with those versions, how we interpret the relations between those is a new dramaturgical question, and perhaps a way out of the Aristotelian understandings of theatre.

\section{References}

Benford, Steve and Gabriella Giannachi. 2008. Temporal Trajectories in Shared Interactive Narratives. In CHI 2008 Proceedings. Stories and Memories, April 5-10, 2008, Florence, Italy, 73-82.

Benford, Steve and Gabriella Giannachi. 2011. Performing Mixed Reality. Cambridge, Massachusetts: MIT Press.

Benford, Steve. 2013. The View From the Other Side: Being a Visiting Professor at BBC R\&D. https://www.bbc.co.uk/rd/blog/2013-04-steve-benford-being-avisiting-professor-at-bbc-rd. Last accessed 19. 07. 2019.

Carlson, Kristin, Prophecy Sun, Shannon Cuykendall, Maria Lantin, Thecla Schiphorst and Greg Corness. 2018. Beyond the Here and Now: Exploring Threaded Presence in Mediated, Improvised Performance. Presence: Teleoperators and Virtual Environments vol. 26, no. 2 (Spring): 97-110. 
Dixon, Steve. 2007. Digital Performance: A History of New Media in Theater, Dance, Performance Art, and Installation. Cambridge, Massachusetts London, England: MIT Press.

Gergen, Kenneth J. 2009. The Challenge of Absent Presence. In Perpetual Contact. Mobile Communication, Private Talk, Public Performance, eds. James E. Katz and Mark Aakhus, 227-241. Cambridge: Cambridge University Press.

Gumbrecht, Hans Ulrich. 2004. Production of Presence. What Meaning Cannot Convey. Stanford, California: Stanford University Press.

Laine, Tarja. 2006. Lars von Trier, Dogville and the Hodological Space of Cinema. Studies in European Cinema vol. 3, no. 2: 129-141.

Lewin, Kurt. 1933. Vectors, Cognitive Processes, and Mr. Tolman's Criticism. Journal of General Psychology vol. 8, no. 2: 318-345.

Manovich, Lev. 2001. The Language of New Media. Cambridge: MIT Press.

Sitaru, Adrian. 2018. Illegitimate. Hungarian Theatre of Cluj. Date of opening: February 17, 2018. https://www.huntheater.ro/en/shows/447/illegitimate/. Last accessed 19. 07. 2019.

Tompa, Andrea. 2018. A hangyák életéból [On the World of Ants]. Színház.net, May 4, 2018. Fragment in English: https://www.huntheater.ro/en/shows/447/ illegitimate/. Last accessed 19. 07. 2019.

Velt, Raphael, Steve Benford and Stuart Reeves. 2017. A Survey of the Trajectories Conceptual Framework: Investigating Theory Use in HCI. In CHI 2017, May 06-11, 2017, Denver, CO, USA, 2091-2105. 


\section{List of Figures}

Figure 1. Stage and audience at the performance of Illegitimate at the Hungarian Theatre of Cluj (2018). Photo: Biró István. (Reproduced with permission.)

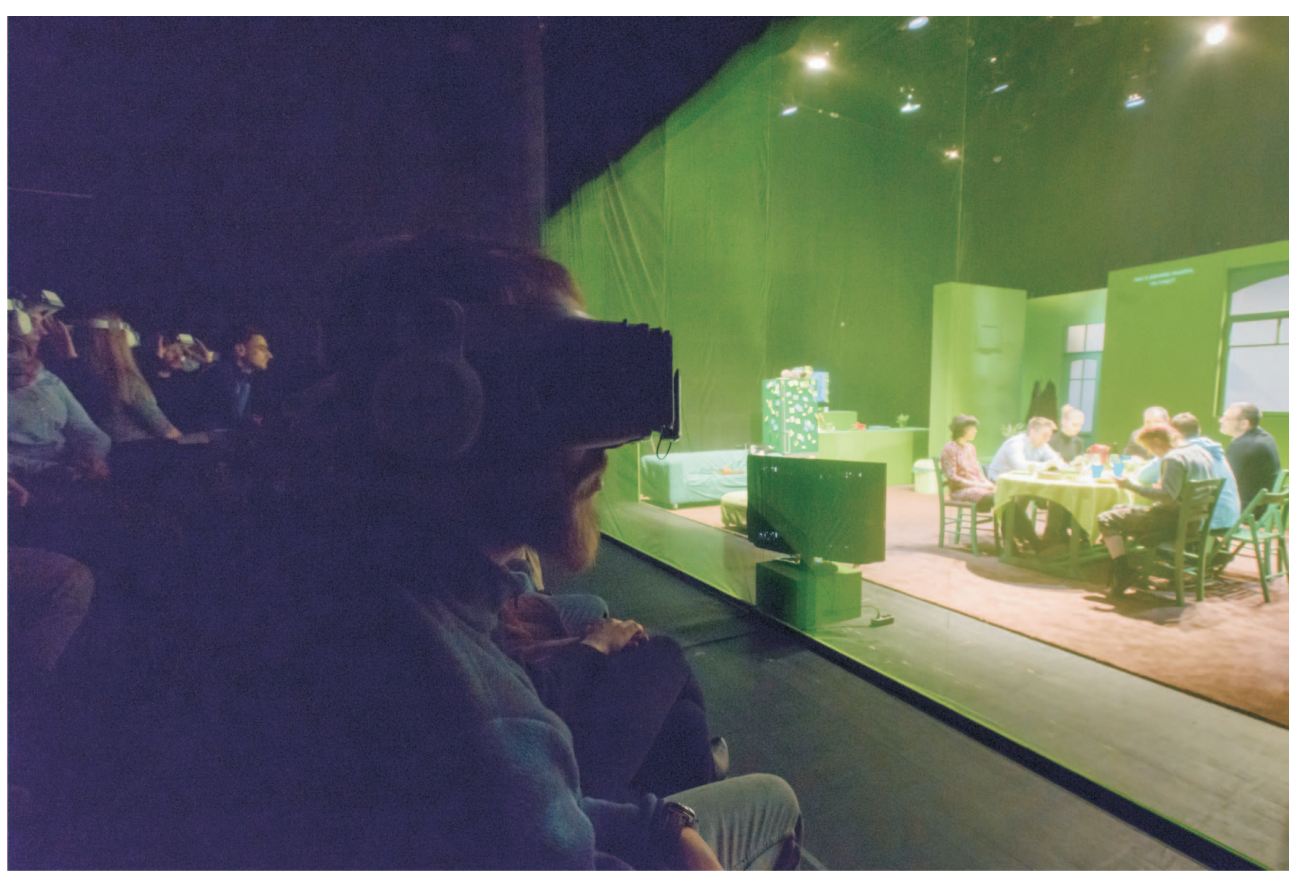

Figure 2. Loops and ruptures in the timeline of the performance of Illegitimate.

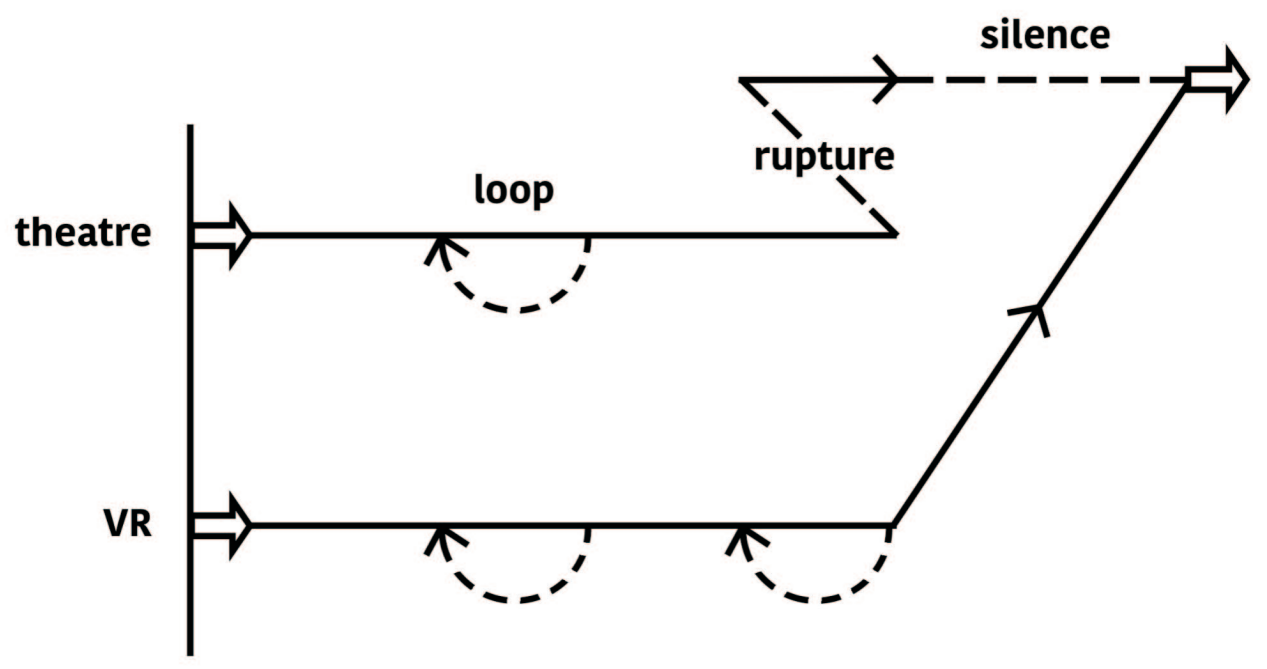


Figure 3. Example of a participant trajectory in the experience of the performance of Illegitimate.

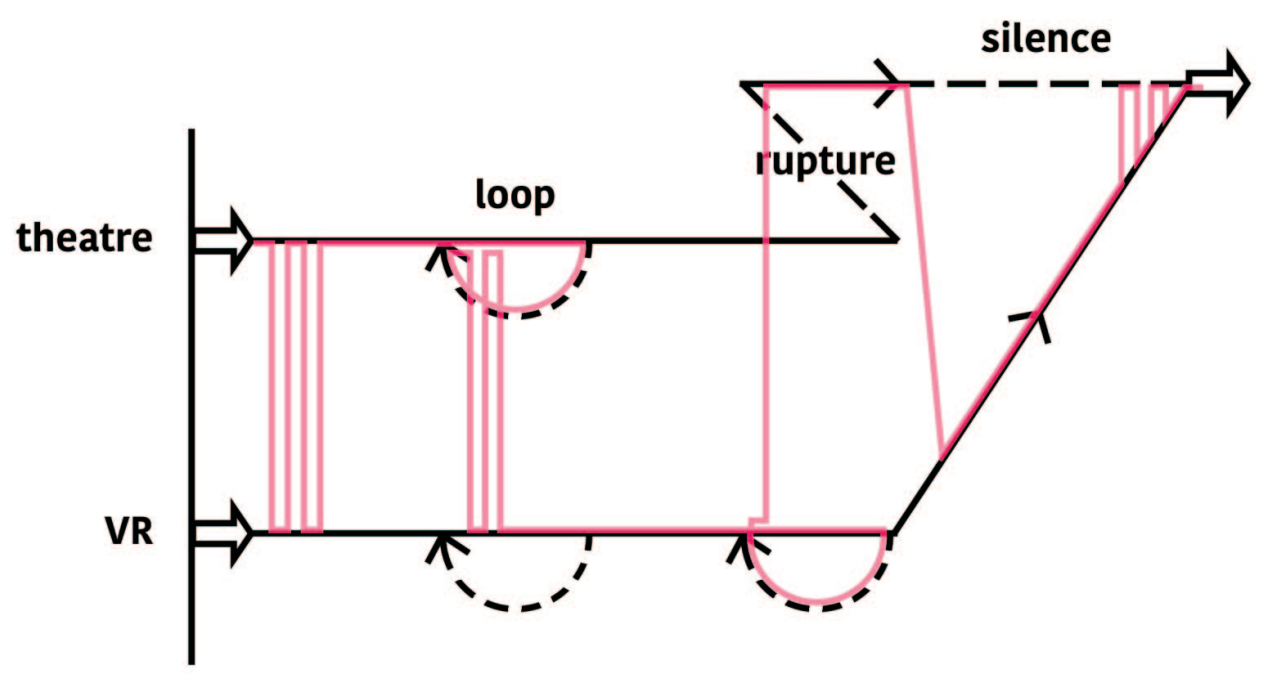

